\title{
Analisis Genangan Akibat Pasang Air Laut di Kabupaten Brebes
}

\author{
Putranto Kondang Wijaya ${ }^{1}$, Denny Nugroho Sugianto ${ }^{1}$, Muslim$^{1}$, Aris Ismanto ${ }^{1}$, Warsito Atmodjo ${ }^{1}$, \\ Rikha Widiaratih ${ }^{1}$, Hariyadi ${ }^{1}$ \\ ${ }^{1}$ Program Studi Oseanografi, Fakultas Perikanan dan Ilmu Kelautan, Universitas Diponegoro, Semarang \\ J1. Prof. Soedarto, S.H., Tembalang, Semarang 50275 Telp/Fax (024)7474698 \\ Email corresponding author: Oceanography@live.undip.ac.id
}

\begin{abstract}
Abstrak
Kecamatan Brebes, Kabupaten Brebes merupakan daerah potensial di bidang pertanian dan perikanan. Sebagian besar wilayah pesisir Kecamatan Brebes digunakan untuk tambak. Namun wilayah ini memiliki masalah yaitu banjir pasang yang menggenangi lahan tambak dan merusak fasilitas umum. Penelitian ini bertujuan untuk mengetahui karakteristik pasang surut, elevasi muka air laut, laju kenaikan muka air laut, dan luas wilayah genangan banjir pasang. Metode yang digunakan adalah metode kuantitatif dengan menggunakan pendekatan Sistem Informasi Geografis (SIG) untuk membuat model genangan banjir pasang dalam bentuk peta. Data yang digunakan berupa data pasang surut, DEM (Digital Elevation Model), data titik genangan banjir pasang, Peta Rupabumi Indonesia tahun 2001, dan citra GeoEye1 perekaman tahun 2017. Diketahui bahwa tipe pasang surut di perairan Kecamatan Brebes adalah campuran condong ke harian ganda dengan elevasi muka air laut yang terukur sebesar $84,2 \mathrm{~cm}$ untuk nilai muka air laut rerata (MSL), 146,44 cm saat pasang tertinggi (HHWL), 21,85 cm saat surut terendah (LLWL). Serta nilai laju kenaikan muka air laut sebesar 3,87 cm/tahun. Sehingga luas wilayah genangan banjir pasang pada tahun 2017 sebesar 4502,23 Ha. Kemudian diprediksi pada tahun 2018 - 2022 luas wilayah genangan akan meluas berurutan tiap tahun sebesar 4690,33 Ha, 4825,11 Ha, 4966,17 Ha, 5049,19 Ha, dan 5114,74 Ha.
\end{abstract}

Kata kunci: Banjir Pasang, Wilayah Genangan, Pasang Surut, Brebes

\begin{abstract}
Brebes District, Brebes Regency is a potential area in agriculture and fisheries. Most of the coastal areas of Brebes District are used for ponds. But this area has a problem is tidal flood, that flooding the ponds and damaging public facilities. This study aims to determine the characteristics of tidal, sea water elevation, sea level rise, and the tidal flood inundation area. The method used is a quantitative method using the Geographic Information System (GIS) approach to create a model of tidal flood inundation area into a maps. The data used to make the model are tides, DEM (Digital Elevation Model), Indonesia Rupabumi maps published in 2001, GeoEyel satellite images recorded in 2017. It is known the tidal type in Brebes District coastal water is mixed tide prevailing semidiurnal with sea level measurements of $84,2 \mathrm{~cm}$ for mean sea level (MSL), 146,44 $\mathrm{cm}$ during high highest water level (HHWL), and 21,85 cm at low lowest water level (LLWL). Rate of sea level rise is calculated at 3,87 cm/year. Inundation area by tidal flood in Brebes District in 2017 is 4502,23 Ha. Then it is predicted that in 2018 - 2022 the area of inundation will extend each year by 4690,33 Ha, 4825,11 $\mathrm{Ha}, 4966,17 \mathrm{Ha}, 5049,19 \mathrm{Ha}$, and 5114,74 Ha respectively.
\end{abstract}

Keywords: Tidal Flood, Inundation Area, Tides, Brebes 


\section{PENDAHULUAN}

Kawasan pesisir utara Provinsi Jawa Tengah merupakan daerah yang rentan terhadap fenomena banjir pasang akibat pengaruh pasang surut air laut. Fenomena tersebut terjadi saat kondisi pasang tertinggi dan menggenangi daerah-daerah yang memiliki elevasi lebih rendah saat pasang tertinggi. Limpasan air laut akan mengalir dengan bantuan gaya gravitasi ke tempat yang lebih rendah sehingga menggenangi daerah tersebut (Marfai et al., 2013).

Kabupaten Brebes terletak di utara barat Provinsi Jawa tengah yang secara geografis terletak diantara $108^{0} 41^{\prime}-109^{0} 11^{\prime}$ Bujur Timur dan $6^{0} 44^{\prime}-7^{0} 21^{\prime}$ Lintang Selatan yang memiliki panjang pantai sekitar 54 $\mathrm{km}$. Sebagian besar wilayah pantainya digunakan untuk usaha pertambakan (BPS Kabupaten Brebes, 2016). Menurut Poernomo (1992) dalam Suwarsito et al., (2017) sebagian besar kondisi geomorfologi pesisir Kabupaten Brebes merupakan wilayah alluvial dengan topografi yang relatif datar. Berasarkan penelitian yang dilakukan Suwarsito et al., (2017) kemiringan lereng di wilayah Kecamatan Brebes tergolong landai cenderung datar dengan dominasi kelerengan $0-3 \%$. Sehingga menurut Wahyudi (2007) daerah dengan kelerengan seperti itu dapat terkena dampak banjir rob. Dampak yang ditimbulkan oleh banjir pasang adalah tergenangnya lahan permukiman, tambak, daratan, dan sawah yang kemudian merusak infrastruktur dan fasilitas umum.

Penelitian ini bertujuan untuk mengetahui elevasi muka air laut serta luas genangan banjir pasang di Kecamatan Brebes pada tahun 2017 dan prediksi luas genangan tahun 2018 - 2022. Diharapkan melalui penelitian ini dapat memberikan informasi untuk peruntukan penggunaan wilayah di lokasi penelitian. Adapun batasan dalam penelitian ini adalah:

1. Banjir pasang yang terjadi disebabkan oleh adanya muka air tertinggi dan kenaikan muka air laut tanpa ada faktor penurunan permukaan tanah.

2. Tidak terdapat adanya pengaruh akibat antisipasi terhadap banjir pasang di lokasi penelitian.

\section{MATERI DAN METODE}

Materi penelitian ini berupa data primer dan data sekunder. Data primer meliputi data hasil pengukuran lapangan pasang surut dengan interval 1 jam selama 15 hari di Pantai Randusanga Indah, Kecamatan Brebes dan data survei titik genangan banjir pasang di Kecamatan Brebes. Sedangkan data sekunder yang digunakan meliputi data pasang surut pengukuran instansi Badan Informasi Geospasial (BIG) stasiun Cirebon bulan Januari 2014 - bulan April 2017, data titik tinggi Kecamatan Brebes pengukuran instansi BIG tahun 2001, Peta Rupabumi Indonesia tahun 2001, dan Citra satelit Geoeye1 tahun 2017.

Penelitian dilakukan dengan metode kuantitatif yang berdasar pada kaidah-kaidah ilmiah yaitu konkret, objektif, terukur, rasional, dan sistematis. Serta data penelitian ini berupa angka dan analisis dalam bentuk model sehingga disebut metode kuantitatif (Sugiyono, 2011). Selain itu, penelitian ini menggunakan pendekatan Sistem Informasi Geografis (SIG) yang menghasilkan gambaran banjir pasang di Kecamatan Brebes dalam bentuk peta.

\section{Metode Pengambilan Data}

Pengukuran data pasang surut lapangan dilakukan dengan menggunakan pendekatan metode cluster sampling, karena pasang surut merupakan fenomena yang terjadi dalam cakupan wilayah yang luas. Pengukuran pasang surut dilakukan dengan mencatat elevasi muka air laut pada skala palem dengan interval 1 jam selama 15 hari. Sedangkan pengambilan data titik genangan banjir pasang dilakukan dengan pendekatan metode purposive sampling. Penentuan titik lokasi genangan banjir pasang ditentukan berdasarkan pengamatan langsung saat banjir pasang terjadi dan berdasarkan keterangan penduduk setempat. Titik tersebut tersebar di tiga desa yang dekat dengan laut. Sebanyak 7 titik terdapat di Desa Randusanga Kulon, 3 titik di Desa randusanga Wetan, dan 2 titik terdapat di Desa Kaliwlingi.

\section{Metode Analisis Data \\ Pasang Surut}

Data pengukuran pasang surut dengan interval 1 jam selama 15 hari diolah dan dianalisa dengan metode Admiralty sehingga mendapatkan komponen harmonik pasang surut berupa $\mathrm{S}_{0}, \mathrm{M}_{2}, \mathrm{~S}_{2}, \mathrm{~N}_{2}, \mathrm{~K}_{2}, \mathrm{~K}_{1}, \mathrm{O}_{1}$, $\mathrm{P}_{1}, \mathrm{M}_{4}$. Komponen tersebut digunakan untuk menentukan tipe pasang surut berdasarkan nilai Formzahl serta nilai elevasi muka air laut berupa HHWL (High Highest Water Level), MSL (Mean Sea Level), dan LLWL 
(Low Lowest Water Level). Berikut persamaan yang dipakai dalam penelitian ini, seperti yang pernah digunakan oleh Fadilah et al. (2014):

1. Mean Sea Level (MSL)

$$
M S L=S_{0}
$$

2. Highest High Water Level (HHWL)

$$
H H W L=S_{0}+A\left(M_{2}+S_{2}+N_{2}+K_{1}+K_{2}+O_{1}+P_{1}+M_{4}+M S_{4}\right)
$$

3. Lowest Low Water Level (LLWL)

4. Nilai Formzahl $(\mathrm{F})$

$$
L L W L=S_{0}-A\left(M_{2}+S_{2}+N_{2}+K_{1}+O_{1}+P_{1}+M_{4}+M S_{4}\right)
$$

$$
F=\frac{A(K 1)+A(O 1)}{A(M 2)+A(S 2)}
$$

Keterangan:

F : Nilai Formzahl

$\mathrm{A}\left(\mathrm{K}_{1}\right)$ : Amplitudo dari anak gelombang pasang surut harian rata-rata yang dipengaruhi oleh deklinasi bulan dan matahari

$\mathrm{A}\left(\mathrm{O}_{1}\right)$ : Amplitudo dari anak gelombang pasang surut harian tunggal yang dipengaruhi oleh deklinasi matahari $\mathrm{A}\left(\mathrm{M}_{2}\right)$ : Amplitudo dari anak gelombang pasang surut harian ganda rata-rata yang dipengaruhi oleh bulan $\mathrm{A}\left(\mathrm{S}_{2}\right)$ : Amplitudo dari anak gelombang pasang surut harian ganda rata-rata yang dipengaruhi oleh matahari

Berikut klasifikasi karakteristik pasang surut berdasarkan nilai Formzahl yang digunakan oleh Mahatmawati et al. (2009):

1. Pasang surut harian ganda jika $\mathrm{F} \leq 0,25$

2. Pasang surut campuran (ganda dominan) jika $0,25<\mathrm{F} \leq 1,5$

3. Pasang surut campuran (tunggal dominan) jika $1,5<\mathrm{F} \leq 3$

4. Pasang surut harian tunggal jika $F>3$

\section{Kenaikan Muka Air Laut}

Pengolahan kenaikan muka air laut dalam penelitian ini menggunakan data pasang surut pengukuran instansi BIG stasiun Cirebon bulan Januari 2014 - bulan April 2017. Data tersebut diolah dengan metode Admiralty untuk mendapatkan nilai muka air laut rerata (MSL) tiap bulannya. Nilai kenaikan muka air laut didapat dengan metode regresi linear sebagai berikut:

$$
\mathrm{Y}=\mathrm{ax}+\mathrm{b}
$$
al (2016):

Kemudian nilai trend kenaikan pertahun dapat dicari dengan persamaan yang dipakai oleh Cahyadi et

$$
\text { Tren pertahun }=\frac{\text { Ymaksimal }- \text { Yminimal }}{\text { Bulan }} \times 12 \text { Bulan }
$$

Adanya penurunan muka tanah (land subsidence) akan mempengaruhi tinggi muka air laut yang terjadi, namun dalam penelitian ini nilai tersebut tidak dimasukkan karena tidak tersedianya data tersebut di lokasi penelitian.

\section{Model Spasial Genangan Banjir Pasang}

Data titik tinggi pengukuran tahun 2001 dari instansi BIG diinterpolasi dengan metode Topo To Raster melalui perangkat lunak ArcMap 10.2 sehingga didapat data DEM (Digital Elevation Model). Model spasial genangan banjir pasang dibuat dengan memasukkan nilai selisih HHWL dan MSL ke dalam modul Raster Calculator. Berikut persamaan yang dimasukkan ke dalam modul tersebut seperti yang digunakan oleh Marfai et al. (2011):

$$
W D=\operatorname{con}(\operatorname{con}([D E M] \leq \text { Elevasi, Elevasi }), \operatorname{con}([D E M] \leq \text { Elevasi, Elevasi })-[D E M], 0)
$$

Keterangan:

WD : Kedalaman air genangan banjir pasang 
DEM : Data ketinggian tanah

Elevasi : HHWL - MSL

\section{HASIL DAN PEMBAHASAN}

Berikut hasil pengolahan data pengukuran pasang surut dengan interval 1 jam selama 15 hari di Pantai Randusanga Indah, Kecamatan Brebes:

Tabel 1. Hasil Perhitungan Komponen Harmonik Pasang Surut Perairan Kecamatan Brebes, Kabupaten

\begin{tabular}{ccccccccccc}
\multicolumn{10}{c}{ Brebes, Jawa Tengah tanggal 16-30 April 2017 } \\
\hline & $S_{0}$ & $M_{2}$ & $S_{2}$ & $N_{2}$ & $K_{1}$ & $K_{2}$ & $O_{1}$ & $P_{1}$ & $M_{4}$ & $M S_{4}$ \\
\hline A (cm) & 84,2 & 23,1 & 11,2 & 8,3 & 13,5 & 3,03 & 7,04 & 4,4 & 1,3 & 1,5 \\
$\mathrm{~g}^{\mathrm{o}}$ & - & 155,7 & 321,8 & 341,3 & 155 & 321,8 & 342,1 & 180 & 48,5 & 137,3 \\
\hline
\end{tabular}

Tipe pasang surut perairan di Kecamatan Brebes berdasarkan nilai F (Formzahl) adalah sebesar 0,59 sehingga termasuk campuran condong harian ganda (mixed tide prevailing semidiurnal). Selain itu, didapat nilai elevasi muka air laut berupa MSL, HHWL, dan LLWL secara berurutan sebesar 84,2 cm, 146,66 cm, dan $21,85 \mathrm{~cm}$. Berikut grafik pasang surut pengukuran selama 15 hari di perairan Kecamatan Brebes ditunjukkan pada Gambar 1.

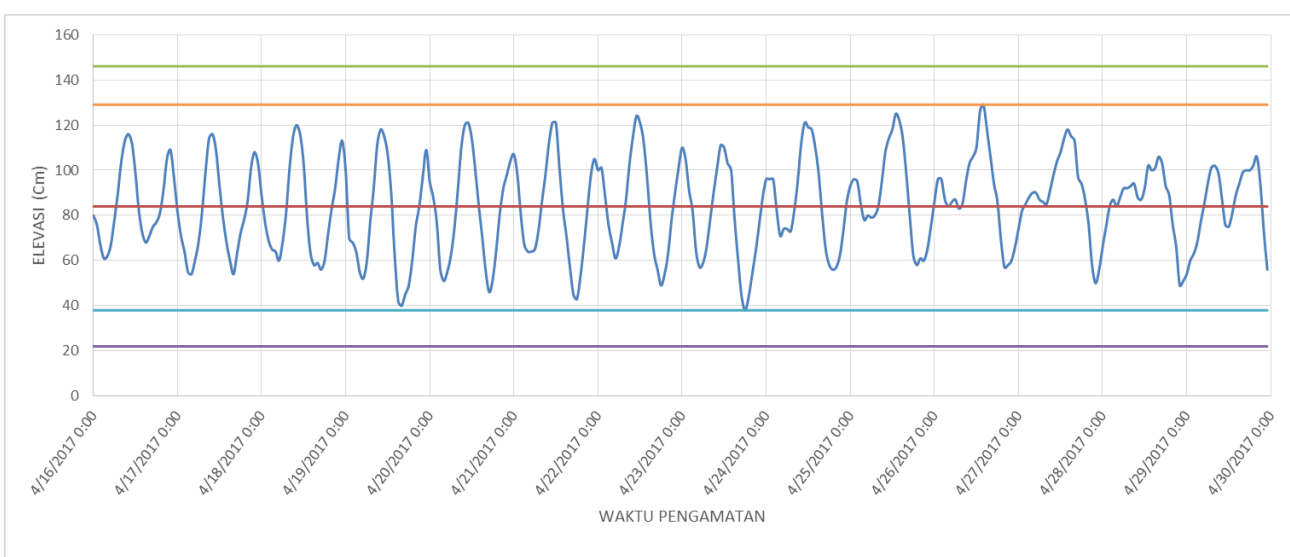

Gambar 1. Grafik Pasang Surut Perairan Randusanga Indah pada 16 April - 30 April 2017 Kecamatan Brebes, Kabupaten Brebes

Nilai elevasi muka air laut yang digunakan sebagai acuan awal untuk model spasial genangan banjir pasang merupakan selisish antara rerata MSL tahunan dan HHWL tahunan sebesar $62,8 \mathrm{~cm}$. Sedangkan untuk membuat prediksi genangan 5 tahun mendatang, nilai tersebut ditambah dengan nilai kenaikan muka air laut berdasarkan pengukuran pasang surut instansi BIG stasiun Cirebon dari tahun 2014 - 2017. Nilai kenaikan muka air laut ini didapat sebesar 3,87 cm/tahun. Berikut merupakan grafik trend kenaikan muka air laut tahun 2014 - 2017 ditunjukkan pada Gambar 2.

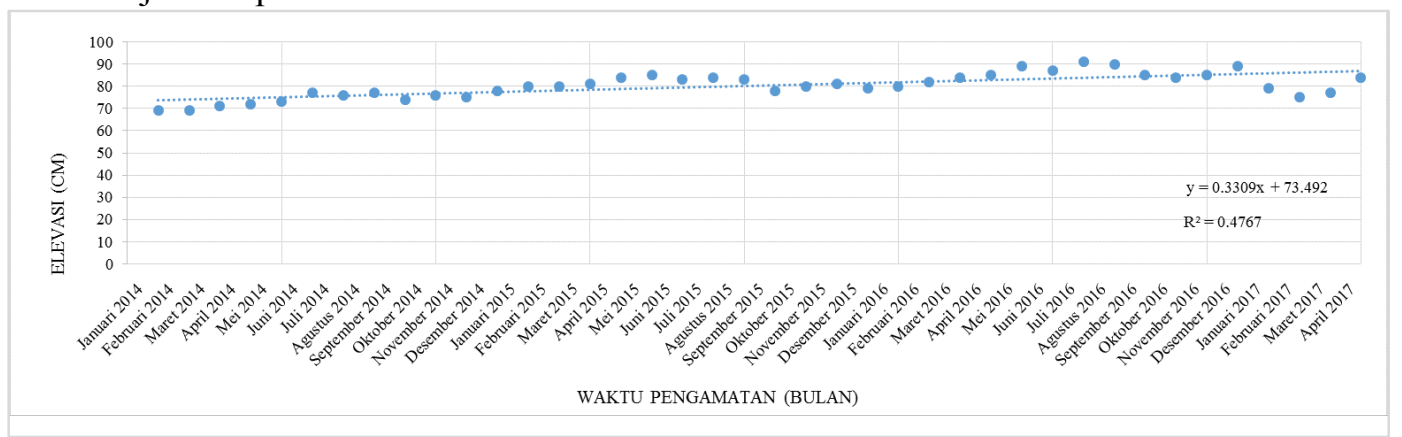

Gambar 2. Grafik Kenaikan Muka Air Laut Tahun 2014 - 2017 
Berdasarkan data titik tinggi yang telah diolah menjadi data DEM, maka dapat diketahui representasi keadaan topografi di lokasi penelitian yang ditampilkan pada Gambar 3.

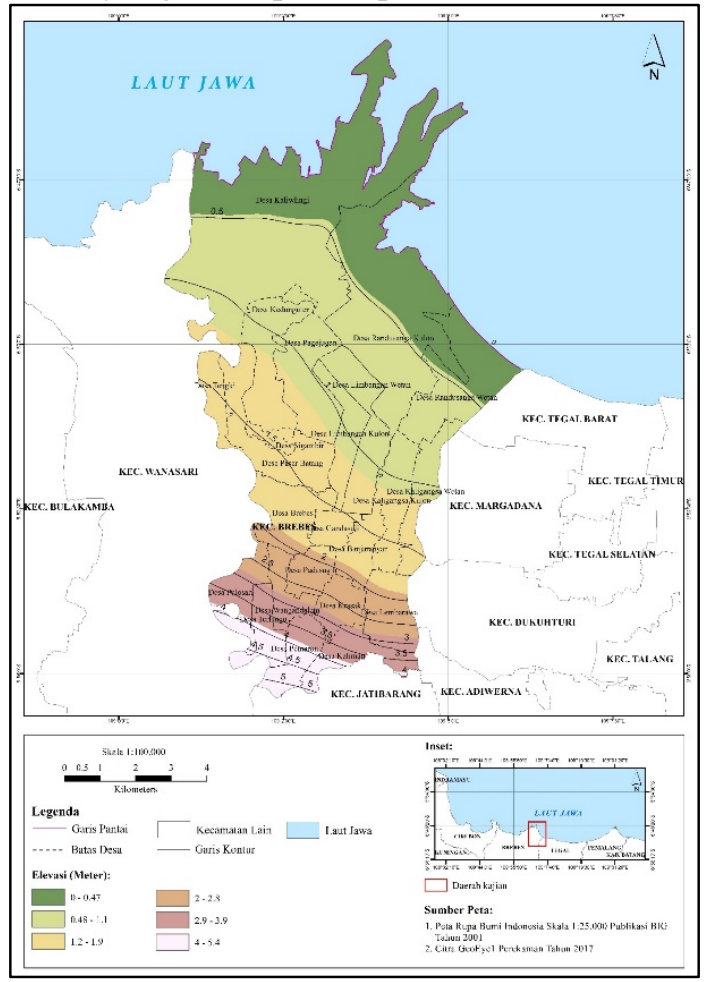

Gambar 3. Peta Elevasi Digital Kecamatan Brebes, Kabupaten Brebes

Hasil model spasial genangan banjir pasang Kecamatan Brebes yang merupakan hasil olahan dari data DEM dan nilai elevasi muka air laut ditampilkan pada Gambar 4.

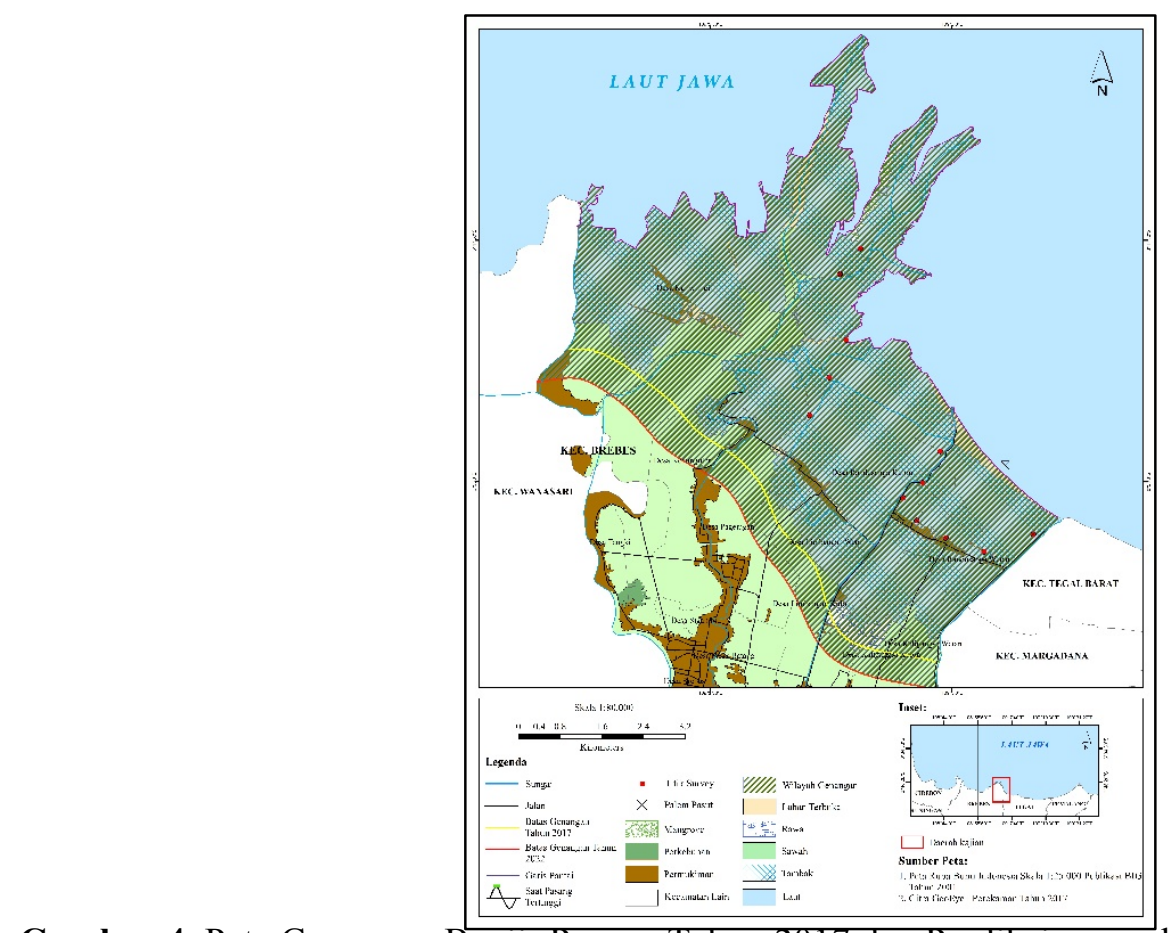

Gambar 4. Peta Genangan Banjır Pasang Tahun 2017 dan Prediksinya pada Tahun 2022 di Kecamatan Brebes, Kabupaten Brebes 
Berdasarkan hasil model spasial genangan banjir pasang, daerah yang tergenang merupakan desa yang terletak di pesisir antara lain Desa Kaliwlingi, Desa Randusanga Kulon, dan Desa Randusanga Wetan. Saat terjadi banjir pasang, air laut menggenangi beberapa lahan seperti permukiman, tambak, lahan terbuka, dan sawah. Luas lahan yang tergenang tersebut ditampilkan pada Tabel 2.

Tabel 2. Luas Lahan (Ha) yang Tergenang oleh Banjir Pasang di Kecamatan Brebes, Kabupaten Brebes pada Tahun 2017

\begin{tabular}{rlc}
\hline No. & Penggunaan Lahan & Luas Genangan (Ha) \\
\hline 1. & Lahan Terbuka & 131,93 \\
2. & Mangrove & 28,76 \\
3. & Permukiman & 95,19 \\
4. & Rawa & 48,24 \\
5. & Sawah & 602,38 \\
6. & Tambak & 3595,73 \\
\hline & Total & 4502,23 \\
\hline
\end{tabular}

Berdasarkan nilai elevasi muka air laut sebesar $62,7 \mathrm{~cm}$ dan kenaikan pertahun sebesar 3,87 cm. Maka prediksi luasan genangan banjir pasang bertambah pada tahun 2018 - 2022. Prediksi luas wilayah genangan banjir pasang untuk 5 tahun mendatang di Kecamatan Brebes ditampilkan pada Tabel 3.

Tabel 3. Prediksi Luas Lahan (Ha) yang Tergenang oleh Banjir Pasang di Kecamatan Brebes, Kabupaten Brebes pada Tahun $2018-2022$

\begin{tabular}{lllllll}
\hline & \multirow{2}{*}{$\begin{array}{c}\text { Penggunaan } \\
\text { No. }\end{array}$} & \multicolumn{5}{c}{ Luasan Genangan (Ha) per Tahun } \\
\cline { 3 - 7 } & \multicolumn{2}{c}{$\mathbf{2 0 1 8}$} & $\mathbf{2 0 1 9}$ & $\mathbf{2 0 2 0}$ & $\mathbf{2 0 2 1}$ & $\mathbf{2 0 2 2}$ \\
\hline 1. & Lahan Terbuka & 131,93 & 131,93 & 131,93 & 131,93 & 131,93 \\
2. & Mangrove & 28,76 & 28,76 & 28,76 & 28,76 & 28,76 \\
3. & Permukiman & 98,59 & 103,23 & 107,17 & 111,89 & 115,73 \\
4. & Rawa & 48,24 & 48,24 & 48,24 & 48,24 & 48,24 \\
5. & Sawah & 787,08 & 917,22 & 772,60 & 55,56 & 56,65 \\
6. & Tambak & 3595,72 & 3595,72 & 3877,47 & 4672,80 & 4733,43 \\
\hline & Total & 4690,33 & 4825,11 & 4966,17 & 5049,19 & 5114,74 \\
\hline
\end{tabular}

Berdasarkan hasil pengolahan pasang surut, diketahui bahwa tipe pasang surut di perairan Kecamatan Brebes merupakan campuran condong harian ganda (mixed tide prevailing diurnal) dengan nilai bilangan Formzahl sebesar 0,59. Menurut Fadilah et al. (2014) tipe tersebut memiliki dua kali pasang dan dua kali surut dalam satu hari. Pada gambar 1 yang menampilkan grafik pasang surut dan elevasi muka air laut perairan tersebut, diketahui bahwa nilai MSL sebesar 84,15 cm, HHWL sebesar 146,44 cm dan LLWL sebesar 21,85 $\mathrm{cm}$. Kemudian terlihat juga bahwa pada saat kondisi pasang purnama yang terjadi pada Tanggal 26 April 2017 yang merupakan awal bulan baru, nilai elevasi yang tercatat merupakan nilai tertinggi yang mencapai $128 \mathrm{~cm}$. Fenomena ini menurut Musrifin (2011) dikarenakan posisi bulan, bumi, dan matahari terletak dalam satu garis sehingga terjadi fenomena berupa spring tides. Nilai muka air laut, tiap tahunnya mengalami kenaikan, hal ini dapat disebabkan karena faktor pencairan es sehingga menambah volume air laut secara global. Berdasarkan perhitungan kenaikan muka air laut, didapati bahwa terjadi kenaikan sebesar $3,87 \mathrm{~cm} /$ tahun dengan periode pengamatan pasang surut selama tahun 2014 - 2017. Nilai tersebut tergolong besar karena tidak adanya koreksi terhadap nilai penurunan permukaan tanah. Menurut Wirasatriya et al. (2006) nilai penurunan muka tanah merupakan faktor yang berpengaruh terhadap nilai kenaikan muka air laut.

Banjir pasang di Kecamatan Brebes yang terjadi merupakan akibat dari pengaruh pasang surut dan diperparah dengan adanya kenaikan muka air laut. Kejadian tersebut terjadi pada saat kondisi pasang purnama. Hal ini dikarenakan pada saat pasang purnama, elevasi muka air laut pasang menjadi lebih tinggi sehingga menggenangi daerah yang memiliki elevasi lebih rendah. Simulasi yang digunakan dalam penelitian ini 
menggunakan elevasi muka air laut setinggi $62,8 \mathrm{~cm}$ untuk genangan pada bulan April tahun 2017. Berdasarkan hasil tersebut diketahui bahwa seluas 4502,23 Ha lahan tergenang. Lahan tersebut didominasi oleh tambak seluas 3595,73 Ha. Tambak merupakan lahan yang memilki saluran yang saling menyambung antar petak lahan, sehingga saat banjir pasang memasuki tambak maka muka air tambak secara keseluruhan akan meningkat. Meningkatnya elevasi muka air pada tambak dapat menggenangi tanggul pembatas sehingga akan merusak tanggul tersebut. Sehingga merugikan pemilik tambak karena harus mengeluarkan biaya perbaikan. Selain tambak, daerah yang tergenang pada simulasi model ini adalah sawah seluas 602,38 Ha, permukiman seluas 95,19 Ha, dan lahan terbuka seluas 131,93 Ha. Terjadinya banjir pasang dapat merusak fasilitas umum seperti tergenangnya tiang listrik, rusaknya aspal pada jalan, dan rumah warga yang terendam sehingga perlu ditinggikan.

Adanya kenaikan muka air laut serta jika tidak ada perlakuan antisipasi terhadap banjir pasang, maka luas genangan banjir pasang akan meningkat. Nilai kenaikan muka air laut sebesar 3,87 cm/tahun akan membuat luasan genangan akan meningkat pada tahun 2018 hingga 2022 secara berurutan seluas 4690,33 Ha, 4825,11 Ha, 4966, $17 \mathrm{Ha}, 5049,19 \mathrm{Ha}$, dan 5114,74 Ha. Namun prediksi ini kurang akurat karena tidak adanya data penurunan permukaan tanah di lokasi penelitian. Sehingga lebih baik jika dimasa mendatang perlu adanya pengukuran penurunan permukaan tanah. Agar dapat diketahui kenaikan muka air laut secara akurat dan diharapkan dampak akibat banjir pasang dapat diminimalisir.

\section{KESIMPULAN}

Kesimpulan dari penelitian ini adalah tipe pasang di perairan ini merupakan campuran condong harian ganda dengan elevasi muka air laut MSL, HHWL, dan LLWL berurutan sebesar 84,15 cm, 146,44 cm, dan $21,85 \mathrm{~cm}$. Nilai laju kenaikan muka air laut yang didapat sebesar $3,87 \mathrm{~cm} /$ tahun. Sehingga didapat luas genangan banjir pasang tahun 2017 seluas 4502,23 Ha. Serta diprediksi pada tahun 2018 hingga tahun 2022 luas genangan banjir pasang di Kecamatan Brebes menjadi 4690,33 Ha, 4825,11 Ha, 4966, 17 Ha, 5049, 19 Ha, dan 5114,74 Ha.

\section{DAFTAR PUSTAKA}

Badan Pusat Satistik (BPS) Kabupaten Brebes. 2016. Brebes dalam Angka 2016. BPS, Brebes, $316 \mathrm{hlm}$.

Cahyadi, N. M., M. J. Lalu, dan H. D. Aryansandah. 2016. Studi Kenaikan Muka Air Laut Menggunakan Data Satelit Altimetri Jason-1 (Studi Kasus: Perairan Semarang). Jurnal Geoid, Vol. 11(2):176-183.

Fadilah, Suripin, dan D. P. Sosongko. 2014. Menentukan Tipe Pasang Surut dan Muka Air Rencana Perairan Laut Kabupaten Bengkulu Tengah Menggunakan Metode Admiralty. Jurnal Maspari., 6(1):1-12.

Mahatmawati D. A., M. Efendy, S. Dwi, A. Hidayah, dan N. Andy. 2009. Perbandingan Fluktuasi Muka Air Laut Rerata (MLR) di Perairan Pantai Utara Jawa Timur dengan Perairan Pantai Selatan Jawa Timur. Jurnal Kelautan., 2(1):33-42.

Marfai, M. A., A. P. Nursakti, H. Taufik, A. W. Nugraha, dan G. Muammar. 2011. Model Kerentanan Wilayah Pesisir Berdasarkan Perubaan Garis Pantai dan Banjir Pasang (Studi Kasus: Wilayah Pesisir Pekalongan). Percetakan Pohon Cahaya, Yogyakarta. $81 \mathrm{hlm}$.

Marfai, M.A., D. Mardiatno, A. Cahyadi, F. Nucifera, dan H. Prihatno. 2013. Pemodelan Spasial Bahaya Banjir Rob Berdasarkan Skenario Perubahan Iklim dan Dampaknya di Pesisir Pekalongan. Jurnal Bumi Lestari., 13(2):244-256.

Musrfin. 2011. Analisis Pasang Surut Perairan Muara Sungai Mesjid Dumai. Jurnal Perikanan dan Kelautan., 16(1): 48-55.

Sugiyono. 2011. Metode Penelitian Kuantitatif, Kualitatif dan R\&D. Alfabeta, Bandung, $330 \mathrm{hlm}$.

Suwarsito dan A.W. Nirwansyah. 2017. Karakteristik Geofisik Lahan Pesisir di Kabupaten Brebes Berbasis Teknologi Sistem Informasi Geografi untuk Pengembangan Budidaya Tambak Udang. URECOL Proceeding. ISBN 978-979-3812-42-7.

Wahyudi, S.I. 2007. Tingkat Pengaruh Elevasi Pasang Surut Terhadap Banjir Rob di Kawasan Kaligawe Semarang. Riptek, 1(1):27-34.

Wirasatriya, A., A. Hartoko dan Suripin. 2006. Kajian Kenaikan Muka Laut sebagai Landasan Penanggulangan Rob di Pesisir Kota Semarang. Jurnal Pasir Laut., 1(2):31-42. 